\title{
PESQUISA EM SAÚDE: Perspectivas narrativistas, métodos e níveis de análise
}

\author{
Health research: Narrative perspectives, methods and levels of analysis
}

\author{
Idilva Germano $^{[a]}$, Carolina Aires de Castro $^{[\mathrm{b}]}$ \\ ${ }^{[a]}$ Doutora em Sociologia, professora do Programa de Pós-Graduação em Psicologia da Universidade Federal do Ceará (UFC), \\ Fortaleza, CE - Brasil, e-mail: idilvapg@ufc.br \\ ${ }^{[b]}$ Psicóloga, Mestranda do Programa de Pós-Graduação em Psicologia da Universidade Federal do Ceará (UFC), Fortaleza, CE - Brasil.
}

\section{Resumo}

Estudos recentes sobre a experiência de si a partir de uma abordagem histórica e culturalmente orientada têm focalizado o papel organizador e constituinte das narrativas, partindo da noção de que as subjetividades são construídas na prática discursiva cotidiana. Uma ideia subjacente aos estudos é que precisamos recorrer às narrativas para dar sentido ao mundo, aos outros e às nossas vidas. Alguns estudos frisam que, ao construírem enredos, as pessoas ordenam temporalmente o vivido, criando certa estabilidade e coerência ao que lhes acontece. Noutros, as narrativas configuram ações sociais estritamente dependentes dos contextos e interações sociais, gerando realidades contingentes e instáveis. A teorização da narrativa desde o giro discursivo e narrativo tem revelado um panorama marcado por uma pluralidade de perspectivas teóricometodológicas de difícil travessia, dadas as diferentes concepções acerca da natureza da narrativa e do self, a respeito dos métodos de abordagem e dos níveis de análise das narrativas sob investigação. Este trabalho revisa a classificação das perspectivas narrativistas sobre o self, de Smith e Sparkes (2008), e a discussão de Murray (2000) sobre os diferentes níveis de análise de narrativas para, em seguida, ilustrar e discutir modos de pesquisar a relação entre linguagem, doença e subjetividade. Conclui-se que, apesar das distinções assinaladas, as pesquisas empíricas exibem significativos pontos de convergência, especialmente no modo como analisam o papel dos contextos intersubjetivos e socioculturais. Quanto aos níveis de análise, as pesquisas têm buscado integrá-los, de modo a obter interpretações mais complexas sobre a experiência do adoecer em seus múltiplos contextos e condições.

Palavras-chave: Pesquisa em saúde e doença. Self. Narrativa. Discurso. Subjetividade. 


\begin{abstract}
Recent studies about the self in a historically and culturally oriented approach have focused the organizing and constitutive role of narratives, parting from the recognition that subjectivities are constructed in daily discursive practice. An underlying idea is that we need to make use of narratives in order to make sense of the world, of others and ourselves. Some studies stress that by constructing plots people give temporal order to lived events creating a certain degree of stability and coherence. Other studies present narratives as social actions strictly dependent on contexts and social interactions, giving form to contingent and instable realities. Narrative theorization, since discursive and narrative turn, has revealed a landscape characterized by an entangled plurality of theoretical and methodological perspectives with different conceptions about the nature of narrative and the self, the methods of approaching these matters and the levels of narrative analysis. This paper reviews Smith and Sparkes' (2008) classification of narrative perspectives on the self and Murray's (2000) discussion on different levels of narrative analysis in order to illustrate and discuss methods of research on the relation between language, illness and subjectivity. We conclude that despite the distinctions presented, empirical research show significant points of convergence, specially in terms of analysis of the role of inter-subjective and socio-cultural contexts. In reference to levels of narrative analysis research has tried to integrate levels to obtain more complex interpretations about the experience of illness in its multiple contexts and conditions.
\end{abstract}

Keywords: Research on health and illness. Self. Narrative. Discourse. Subjectivity.

\section{Estudos narrativos em psicologia: Fundamentos e desdobramentos}

Para aquele interessado em enveredar no campo dos estudos de Psicologia Narrativa, o empreendimento pode parecer bastante confuso, considerando as variadas perspectivas que vêm se consolidando no terreno de pesquisas narrativas desde a publicação do hoje clássico Narrative Psychology, editado por Theodore Sarbin (1986). Naquele momento, o termo "psicologia narrativa" foi usado, de modo abrangente, para designar o recente interesse da Psicologia pela natureza narrativa da ação humana e para reunir teóricos comprometidos em dirigir sua atenção para a produção, narração e compreensão de histórias.

Desde os anos 80 do século XX, os estudos de narrativas avançaram consideravelmente no campo da psicologia social, da personalidade, do desenvolvimento, da psicologia cognitiva, da psicologia clínica, lado a lado com muitas disciplinas afins (Sociologia, Antropologia, Filosofia, Comunicação, Linguística, Literatura, Medicina etc.). Tais estudos ramificaram-se em muitas linhagens distintas, muitas vezes em oposição quanto a pressuposições, objetivos, unidades de análise e outros pontos. $\mathrm{O}$ campo mostra-se, de fato, tensionado por tais perspectivas que, ao longo do tempo, apartaram ensaístas antes reunidos sob uma mesma rubrica. Embora ainda hoje haja referência à psicologia narrativa em sentido lato, como no panorâmico site Narrative Psychology: Internet and Resource Guide < http:/ /web.lemoyne.edu / hevern / narpsych / narpsych.html>, os trabalhos no campo revelam uma pluralidade contrastante de tradições e influências, levando inclusive à identificação de narrativistas com linhagem teórico-metodológica particular, distinta de outras escolas e movimentos também interessados na construção discursiva e narrativa da experiência humana (como o construcionismo social, a psicologia dos construtos pessoais e as teorias baseadas na noção de dialogismo).

Nessa trajetória, as escolas de psicologia que exploram a centralidade da narrativa, em diálogo com outras disciplinas, vêm promovendo uma remodelação do próprio conceito de narrativa, levando boa parte dos teóricos a minimizar o foco representacional estreito, isto é, a narrativa como espelho de uma realidade preexistente fora da prática discursiva, e realçar o aspecto construtivo da narração humana. 
Dada a ubiquidade da narrativa na teorização e na pesquisa psicológica e sociológica, várias tentativas vêm sendo feitas para distinguir classes ou tipos de estudos com narrativas, a partir da análise comparada de determinados critérios, tais como pressupostos ontológicos e epistemológicos, molduras teóricas e metodológicas, conceito de narrativa adotado e outros (Somers, 1994; Stanley \& Temple, 2005).

Uma abordagem bastante útil para a compreensão dos tipos de estudos sobre o self e identidade narrativa é fornecida por Smith e Sparkes (2008), que propõem cinco perspectivas alinhadas num continuum, conforme a dominância atribuída à esfera individual/pessoal ou social/relacional na compreensão dos fenômenos envolvidos na constituição sociocultural da experiência de si.

Nosso primeiro objetivo é discutir a tipologia original Smith e Sparkes (2008) e a classificação de Murray (2000) sobre o nível de análise de narrativas adotado em pesquisas na área de saúde. O segundo objetivo é selecionar alguns exemplos de pesquisas que estudam narrativas no campo da saúde (em psicologia, sociologia, medicina, antropologia, enfermagem e outras), identificando-os, segundo as indicações desses autores. Esses procedimentos pretendem esclarecer as particularidades dessas perspectivas por meio de exemplos de pesquisas qualitativas publicadas em periódicos que abordam questões de saúde e doença. Com isso, almejamos detectar as dificuldades e lacunas que ainda permanecem na tipologia das cinco perspectivas narrativas, quando utilizadas para distinguir os tipos de pesquisas em curso no campo da saúde.

\section{Níveis de análise da narrativa e perspectivas teóricas acerca da construção narrativa do self e da identidade}

Murray (2000) empreende uma revisão e classificação dos estudos narrativos em psicologia da saúde sugerindo quatro níveis de análise de narrativas: pessoal, interpessoal, posicional e social ou ideológico. No nível pessoal de análise, as teorias focalizam como os indivíduos organizam sua percepção, a avaliação de seu contexto social e seu comportamento nesse ambiente. No nível interpessoal, busca-se deslocar o ponto de vista da elaboração psíquica (no plano cognitivo e afetivo) do indivíduo para o contexto interpessoal, que envolve narrador e ouvinte, pressupondo-se que o sentido é produzido num contexto comunicativo, isto é, com locutor e receptor ativos. Deste modo, pesquisadores passam a frisar o papel desempenhado pela situação da conversação na produção de conhecimento e na modelação das narrativas, e também por outros contextos mais amplos de interação além da situação imediata da interlocução.

No nível posicional de análise, o foco dá-se sobre as diferentes posições ou características sociais dos atores em interações situadas. Aqui se consideram como as diferentes posições sociais dos sujeitos (diferenças prévias à interação) afetam a produção de histórias. Segundo Murray (2000), alguns trabalhos em psicologia da saúde exploram como o fato de o pesquisador ou entrevistador ser saudável coloca o doente na situação de justificar sua doença para alguém que potencialmente porta visão distinta, senão dominante. Esses estudos enfatizam os elementos de poder e dominação embutidos nas narrativas de adoecimento, buscando desvelar o modo como as diferentes posições dos falantes estão a serviço de propósitos pessoais, sociais e políticos.

No nível social ou ideológico de análise, o centro das preocupações são as ideologias da sociedade, sistemas de crenças e representações mais amplas disseminados socialmente. Exemplo clássico são as pesquisas em representações sociais, que focalizam como as narrativas produzidas socialmente modelam as concepções de doença em comunidades específicas. Noutros estudos, importância é dada às representações midiáticas de doença e como elas forjam o senso comum.

Smith e Sparkes (2008) distinguem cinco perspectivas sobre a construção narrativa da subjetividade que compartilham a visão de que a experiência de si está estreitamente conectada a contextos sociais, culturais, históricos e políticos mais amplos: a psicossocial, a intersubjetiva, a dos recursos historiados (storied resources), a dialógica e a performativa. Essas perspectivas são organizadas num eixo direcional, conforme menor ou maior densidade é atribuída à dimensão pessoal/ individual ou à relacional/social como determinante ou origem da identidade narrativa.

A perspectiva psicossocial caracteriza-se pelo primado do indivíduo e de sua interioridade. Defende a centralidade da experiência e do mundo interno do indivíduo, entendendo-o como agente consciente que reflete e articula as histórias possíveis 
que podem ser contadas como episódios de sua biografia. Nesse sentido, as narrativas são concebidas como estruturas cognitivas internas ou psicológicas que podem dar acesso a estados mentais e experiências privadas do indivíduo. Aqui a noção de identidade ou self é pensada como história de vida internalizada que se desenvolve ao longo do tempo mediante autorreflexão. As pessoas precisam de um sentido de unidade, coerência e ordem vivencial para seu bem-estar psicológico, e isso é alcançado mediante a construção de narrativas que articulam e tornam significativos os elementos fragmentados da experiência. Ao fixar o locus do "eu" no indivíduo (na "cabeça" das pessoas), ainda que se conceba sua inserção sociocultural, a perspectiva psicossocial é caracterizada como densamente focada no indivíduo e fracamente no social, em comparação com outras abordagens.

A perspectiva intersubjetiva aproxima-se mais da dimensão social/relacional da construção de si do que a posição anterior e postula a interdependência intersubjetiva. Os estudos dessa linha concebem que a pessoa nasce como sujeito privado e, no contato com os outros indivíduos na sua cultura, mentalmente vai assumindo os papeis e atitudes dos outros em relação à sua pessoa. A pessoa experimenta-se apenas indiretamente a partir do ponto de partida geral do grupo social a que pertence e dos indivíduos que compõem esse grupo (Smith \& Sparkes, 2008, p. 14). Nessas teorias, bastante influenciadas pelo interacionismo simbólico, o indivíduo costuma ser visto como a fonte da identidade e também um veículo da cultura. Essas teorias tendem ao equilíbrio no que concerne às origens da autocompreensão, entendida como fundamentalmente relacional e transacional.

Na perspectiva dos recursos historiados, a balança tende a pender mais para a dimensão social da identidade, cuja origem é atribuída a uma matriz de recursos narrativos acumulados. Essa perspectiva tende a ver as pessoas como amplamente imersas na cultura, de certa forma, como se a cultura "falasse" através de suas histórias e corpos (Smith \& Sparkes, 2008 , p. 16). Nesse sentido, as narrativas são ações sociais e devem ser analisadas em termos dos recursos culturais empregados pelos indivíduos para construí-las, das funções interpessoais e institucionais que elas desempenham e de sua distribuição social. Assim, os pesquisadores tendem a se preocupar com os contextos mais amplos vinculados à narração: momento histórico do relato, raça, classe, gênero e outros sistemas, cosmovisões e discursos sociais manipulados pelo narrador para dar conta do mundo e de si mesmo (Riessman, 1993, p. 21). O self, portanto, é abordado como algo que é criativamente elaborado, em relação direta (via diálogo) ou indireta (nas redes de sentido implícitas na linguagem) com uma comunidade de interlocutores. As biografias e histórias pessoais dependem de versões prévias disponíveis no ambiente cultural, incluindo "as expectativas sobre uma trajetória de vida adequada" (Riessman,1993, p. 18). Em resumo, ainda segundo Riessman (1993), as histórias são lugares para a identidade e construção de si.

A perspectiva dialógica está mais próxima do fim do continuum proposto por Smith e Sparkes (2008), reunindo estudos que tendem a minimizar as origens individuais da identidade narrativa. Ênfase é dada aos processos sociais em curso e a noção de self é formulada em termos de descentramento. A condição relacional e as vozes coletivas precedem a individualidade e a pessoalidade. Bakhtin tende a inspirar essa linha teórica, que assimila as suas ideias de incompletude, abertura e indeterminação das relações constitutivas da subjetividade. A proposta do self dialógico, de Hermans (2001), por exemplo, concebe o self como uma multiplicidade dinâmica e relativamente autônoma de posições do Eu. O modelo teórico focaliza a dimensão espacial, negligenciada por outras abordagens narrativistas que se concentraram na dimensão temporal da identidade narrativa. Os termos "posição" e "posicionamento" evocam a natureza espacial da experiência de si que é concebida como multivocal, heterogênea e conflitiva. Contra a idéia do cogito cartesiano, que formula o $\mathrm{Eu}$ como instância única centralizada, o self dialógico pressupõe que há várias posições do Eu que podem ser ocupadas por uma mesma pessoa. Pesquisas na perspectiva dialógica procuram, desse modo, "investigar como se dão as inter-relações entre as posições assumidas pelo e atribuidas ao participante", com o objetivo de "compreender como se articulam continuidade e descontinuidade de si nesse jogo de posições" (Silva, 2003, p. 84, grifo da autora).

A perspectiva performativa ocupa o fim do continuum, abraçando uma posição francamente não individualista e fortemente relacional. Nessa perspectiva, as narrativas são consideradas práticas discursivas que cumprem funções sociais em contextos situados de interação. A condição relacional precede a individualidade, a interioridade 
e as experiências vividas. Quando alguém age, manifesta uma história de relações, isto é, a história da sociedade e da cultura em que está mergulhado. As identidades pessoais não estão "dentro da cabeça", nem "lá fora", mas são praticadas mediante a narração de histórias e outras atividades desempenhadas conjuntamente em relações sociais situadas. Pesquisadores orientados por tradições tais como etnometodologia, análise da conversação, análise de discurso e psicologia discursiva dão particular atenção às questões da "explicabilidade" (accountability), às descrições e relatos que as pessoas produzem sobre si e sobre o mundo nas interações (que são considerados constituintes da realidade). Essa perspectiva resulta numa concepção das subjetividades como múltiplas, fragmentadas, inacabadas, mutantes, essencialmente contingentes.

\section{Pesquisas narrativas no contexto da saúde/doença: Identificação das perspectivas adotadas em termos da construção sociocultural da experiência de si e do nível de análise das narrativas}

\section{Perspectiva psicossocial}

A perspectiva psicossocial no campo da experiência da saúde/doença costuma explorar o que Murray (2000) chama de nível pessoal de análise das narrativas. A abordagem fenomenológica está mais associada a esse nível de análise, que tende a dominar os estudos em psicologia narrativa. $\mathrm{O}$ argumento central é que durante e depois de enfermidades, não só o corpo mas também a identidade pessoal está ameaçada, de modo que os indivíduos recorrem às narrativas para reconstruir um sentido coeso de seu corpo e de sua pessoa (Crossley, 2000). Movidos pela noção de que os homens criam intrigas a fim de enfrentar o caos e o fluxo da vida, esses estudos tendem a analisar as narrativas na perspectiva do impacto da doença sobre a vida pessoal do doente, sobre a perda e a reconstituição do senso de si mesmo e o papel organizador, terapêutico e de empoderamento das narrativas. Aqui se concebe a doença como evento que desestabiliza a vida e o senso de unidade biográfica do doente, e as narrativas como recursos que não somente dão voz a esse corpo/self transformado, como também permitem a recons- tituição de si e o enfrentamento público da nova condição. Muitas vezes, a preocupação com a dimen-são biográfica do adoecimento é orientada por conceitos tais como: ruptura biográfica (biographical disruption), de Bury (1982), perda do self, de Charmaz (1983), e reconstrução narrativa, de Williams (2001). Essa preocupação pode ser acompanhada, a título de ilustração, em trabalhos mais recentes que receberam direta ou indiretamente a influência desse arcabouço conceitual: Rajaran (1997), sobre o impacto dos episódios de hipoglicemia entre diabéticos e sua família; Kierans (2005), sobre as narrativas de pacientes com falência renal; Young, Dixon-Woods, Findlay e Heney (2002), sobre a desestabilização biográfica entre mães de filhos com câncer; e Sutton e Treloar (2007), sobre como viver com hepatite C.

Esses estudos tendem a investigar a experiência do adoecer a partir "de dentro" (das percepções e relatos dos informantes sobre o que lhes ocorreu com a irrupção da enfermidade), considerando particularmente a esfera ideacional de produção de sentido (o que as pessoas relatam) e seus estilos de pensar ou modos de organizar cognitivamente a experiência da enfermidade. Muitos trabalhos são fenomenologicamente orientados e podem empregar a análise fenomenológica interpretativa, IPA (Interpretive Phenomenological Analysis), método de análise desenvolvido por J. A. Smith e colaboradores (Smith \& Osborn, 2008). O método pressupõe o interesse do pesquisador no "mundo psicológico" do informante, que pode se dirigir para as "crenças e construtos revelados ou sugeridos pela fala do respondente" ou para a história que ele conta, considerada aqui representativa de parte da sua identidade (Smith \& Osborn, 2008, p. 66). Como exemplos de pesquisa utilizando IPA, podemos citar o estudo de Crossley (2000) com portadores de HIV, o de Goodman, Morrisey, Graham e Bossingham (2005) com portadores de lupus eritema-toso sistêmico, e o de Edwards, Thompson e Blair (2007), sobre mulheres portadoras de síndrome de fadiga crônica.

Incluímos na perspectiva psicossocial o estudo de Caprara e Veras (2005) com mães de crianças portadoras de epidermólise bolhosa (EB) congênita, uma doença grave e rara com grande impacto para as vítimas e seus cuidadores. Inspirado na hermenêutica fenomenológica de Paul Ricoeur, o foco é a análise temática das narrativas: a experiência 
do diagnóstico, o medo, as dificuldades do tratamento, a transformação da rotina doméstica e o estigma. Também se enquadra o trabalho de McIntosh e McKecaney (2000) sobre narrativas de recuperação de dependentes de drogas, que se inspira na tese de Giddens (1991) de que a identidade pessoal reside na capacidade de o indivíduo manter sua autobiografia. Os pesquisadores buscam entender a natureza das histórias individuais dos informantes e em que medida a narração dessas histórias poderia ser parte do processo de recuperação. Subentendida está a crença de que as narrativas de recuperação são parte importante do processo de construção e reconstrução do senso de self.

A atenção à construção/reconstrução de si, ao trabalho biográfico associado às alterações do corpo e concepções de tempo, sofrimento e senso de continuidade e descontinuidade do eu e aos estilos de enfrentamento da enfermidade estão presentes em muitos estudos de psicólogos e sociólogos que se valem do método da teoria fundamentada (grounded theory). Exemplos da aplicação do método são numerosos; para ilustração do método em psicologia da saúde, sugerimos o estudo de Nochi (2000), que examina narrativas de pacientes com traumatismo craniano, e o de Shapiro, Angus e Davis (1997), sobre relatos de mulheres sobreviventes do câncer de mama.

\section{Perspectiva intersubjetiva}

A perspectiva intersubjetiva na saúde tende a explorar mais concretamente o âmbito interpessoal de análise das narrativas, adotando a classificação de Murray (2000). Mas também podemos afirmar que o nível ideológico também é alcançado na perspectiva intersubjetiva, uma vez que os estudos também se preocupam com "os sistemas de crenças e representações" da sociedade que orientam as histórias e repertórios dos narradores.

Smith \& Sparkes (2008) citam Ezzy como autor que oferece uma formulação contemporânea à perspectiva, ao integrar reflexões do interacionismo simbólico de George Herbert Mead e a hermenêutica de Ricoeur. Em seu estudo com portadores de HIV, Ezzy (2000, p. 608) explicita sua visão de narrativa: "a construção metafórica de uma história sobre o passado, presente e futuro" que é "elaborada ao longo da entrevista". Baseado na concepção interacionista, o autor confirma que as histórias levantadas em seu estudo são construtos em processo e incompletas, que exibem a desordem e as contradições do próprio ato de narrar. Seu estudo desenvolve indutivamente, via teoria fundamentada, uma tipologia das narrativas empregadas por 45 informantes, que focaliza o aspecto temporal e espiritual da experiência do adoecer. Os três tipos encontrados são as narrativas lineares de reparação ou restabelecimento, as narrativas lineares de caos e as narrativas polifônicas. Cada tipo tende a exprimir um modo específico de lidar com a finitude, de conceber o controle sobre a doença e a vida, de agir no presente e de sentir esperança em relação ao futuro. Ezzy segue, então, no sentido de estabelecer comparações entre cada tipo de narrativa e os sistemas de crenças religiosas identificados no grupo de entrevistados e numa pesquisa quantitativa anterior com a população de onde os entrevistados foram selecionados. Essas comparações são então discutidas em termos da literatura sobre a relação entre religião, reflexividade e experiência temporal, incluindo questões vinculadas ao enfrentamento do risco e da incerteza na vida moderna. Além do contexto de interação da entrevista, os contextos mais abrangentes vinculados ao campo sociocultural do narrador e do intérprete são levados em consideração na compreensão das narrativas produzidas.

Com uma tendência equilibrada quanto à equação indivíduo/mundo sócio-cultural, os estudos sobre a experiência da saúde e da doença orientados pela psicologia cultural buscam fundir o contexto individual e o cultural de análise. $\mathrm{Na}$ antropologia, a sensibilidade da psicologia cultural leva o pesquisador a identificar os conceitos de experiência-próxima que organizam e ajudam a compreender o funcionamento psicológico efetivo de uma pessoa ou grupo de pessoas ${ }^{1}$. Schweder e Sullivan (1993,

\footnotetext{
1 Para Geertz (1999,p. 87), “um conceito de 'experiência próxima’é, mais ou menos, aquele que alguém - um paciente, um sujeito, em nosso caso um informante - usaria naturalmente e sem esforço para definir aquilo que seus semelhantes vêem, sentem, pensam imaginam etc. e que ele próprio entenderia facilmente, se outros o utilizassem da mesma maneira. Um conceito de 'experiência distante' é aquele que especialistas de qualquer tipo - um analista, um pesquisador, um etnógrafo, ou até um padre ou um ideologista - utilizam para levar a cabo seus objetivos científicos, filosóficos ou práticos. 'Amor' é um conceito de experiência próxima; “catexia em um objeto” de experiência-distante.”
} 
p. 507) assinalam as diferenças culturais entre grupos e etnias encontradas em pesquisas sobre a significação da saúde e da doença (que incluem a experiência diferenciada de sintomas fisiológicos e emocionais) e resumem as metas dessa linhagem de estudos: “[...] revelar os significados implícitos que dão forma a processos psicológicos, examinar a distribuição desses significados entre grupos culturais e identificar o modo de sua aquisição social."

A sensibilidade para a experiência-próxima e para significação cultural do adoecimento pode ser acompanhada no trabalho do antropólogo e médico Arthur Kleinman (1988, p. 97), que parte da distinção entre a experiência subjetiva do malestar e do adoecer vivida pelo paciente (conceito de illness) e a noção biomédica do especialista sobre a enfermidade, que frisa a alteração na estrutura e no funcionamento fisiológicos (conceito de disease):

Cada paciente traz ao médico uma história. Essa história mergulha a doença numa rede de significados que fazem sentido apenas no contexto de uma vida particular. Mas para entender essa vida e a experiência do adoecer que ela cria, nós precisamos relacionar vida e adoecimento a contexto cultural.

\section{Perspectiva dos recursos historiados}

Nessa perspectiva, os estudos no contexto do adoecimento focalizam o modo como pacientes, seus familiares, médicos e cuidadores valem-se de narrativas e discursos social e historicamente disponíveis para elaborar sua compreensão da doença, da identidade pessoal, do tratamento, do futuro e outros temas correlatos. Particular atenção é dada às tecnologias de construção de si, analisando o modo como os conceitos de experiência-próxima (concepções comuns ou leigas) e de experiênciadistante (saberes especializados) mediam e condicionam a narração e, portanto, a inteligibilidade dos narradores. Nessa linha de investigação, Sparkes e Smith (2002), em estudo com ex-atletas de rugby que sofreram lesão de medula, tornando-se paraplégicos, identificam o papel dominante de certas narrativas, tais como a narrativa ocidental da cura: "ontem eu era saudável, hoje estou doente, amanhã estarei saudável novamente". A narrativa tradicional que vincula a identidade atlética à masculinidade heroica e viril também é interpretada como recurso que pode manter o deficiente emperrado em visões inflexíveis, pessimistas ou mesmo irrealistas sobre o curso da doença, sobre sua identidade pessoal e masculinidade.

A sensibilidade para os recursos historiados em contexto de adoecimento pode ser acompanhada nos estudos que analisam narrativas em relação aos discursos de gênero, classe, raça, etnia, sexualidade e outras balizas socioculturais. Nessa linha, Chapple e Zibland (2002) examinam questões de masculinidade em pacientes com câncer de próstata, observando que o discurso "homens não choram" parece exercer papel significativo na autocompreensão dos informantes.

É importante ressaltar que os estudos na perspectiva dos recursos historiados, embora reconheçam o peso das narrativas institucionais na elaboração de narrativas do self, partem da noção de que as identidades configuram empreendimento dos narradores em sua prática cotidiana. O processo é concebido como de mão dupla, não determinista, evitando-se essencializar as balizas fornecidas pelos contextos institucionais. Ao comentarem narrativas de participantes de um grupo de Alcoólicos Anônimos, Holstein e Gubrium (2000, p. 180-181) mostram a variabilidade das histórias produzidas, apesar do mapa ou estoque comum de recursos interpretativos (léxico, temas e linhas de enredo) da filosofia e dos rituais dos Doze Passos. Os autores afirmam que "recursos disponíveis certamente não determinam como selves são narrados; circunstâncias individuais, particularidades biográficas, variabilidade da experiência, e inventividade interpretativa e discrição estão em jogo em cada momento".

A perspectiva dos recursos historiados tende, portanto, a integrar vários níveis de análise da narrativa mencionados por Murray, ao examinar os vários contextos e recursos narrativos que estruturam, como matéria-prima, as narrativas pessoais.

\section{Perspectiva dialógica}

A teoria dialógica tem sido amplamente utilizada em pesquisa psicológica em várias disciplinas, tais como psicoterapia, teoria da personalidade, psicologia do desenvolvimento, estudos transculturais, teoria crítica e outros.

Um tipo de pesquisa dialógica na área de saúde e doença tende a analisar a peculiaridade dos processos dialógicos envolvidos em quadros 
patológicos, tais como nas psicoses. É o caso do trabalho de Lysaker e Lysaker (2002, p. 208) que examinam a ruptura no senso do self de pacientes esquizofrênicos, à luz da teorização de Hermans e outros sobre a formação dialógica do self. Sendo o self concebido como processo contínuo de redefinição e reordenamento operado mediante diálogos internos e externos, os autores sugerem que a experiência subjetiva de incoerência pessoal na esquizofrenia deve-se ao colapso da capacidade de manter um diálogo interno permanente. Tal incapacidade leva a experiência de si a resultar ora numa "organização do self vazia ou estéril", ora numa "cacofonia interna", ora em "autoconstruções dominadas por monólogos rígidos e estanques". Com intenção de contribuir para formas de atendimento mais eficazes no campo da saúde mental, alguns estudos examinam o potencial de algumas atividades e recursos para promover ou recuperar a capacidade dos pacientes de dialogar interna e externamente. Um desses recursos é a escrita de "diários dialógicos", em que o paciente escreve livremente suas reflexões e sentimentos e esses conteúdos são posteriormente assunto de conversa, não com fins de diagnóstico, mas de expandir as verbalizações e o trabalho reflexivo do paciente (Durgahee, 2002).

No campo da terapia familiar, a perspectiva dialógica tem recentemente explorado a polifonia das vozes e as formas de posicionamento subjetivo que se dão na relação terapeuta-cliente e nos contextos institucionais mais amplos envolvidos na saúde e na doença. Fundamentados em teóricos como Bakhtin, Volosinov, Hermans e outros que compartilham a noção de que o sentido é derivado das práticas relacionais, esses estudos tendem a reconhecer o diálogo como elemento essencial na relação terapêutica e na experiência de cura, e a propor formas de atuação que promovam o "engajamento polifônico entre as vozes" do cliente, do terapeuta, da equipe profissional, da rede familiar, comunitária e outras (Seikkula \& Trimble, 2005, p. 463). A intenção de remover os efeitos de dominação por parte do terapeuta, adotando a postura de não saber e, assim, evitando uma atitude "monológica", surge como imperativo ético nas terapias de base narrativista-dialógica.

Numa linha de pesquisa menos comum, o self dialógico pode ser explorado a partir da perspectiva do próprio profissional, isto é, da "conversação interna do terapeuta", marcada por descontinuidades entre a posição de estar receptivo à situação imediata do encontro com o cliente e de escutar suas histórias ("self vivenciador") e a posição do profissional reflexivo que responde às solicitações do cliente na interação ("self profissional") (Rober, Elliot, Buysse, Loots \& De Corte, 2008, p. 406). De qualquer modo, as pesquisas dialógicas são bastante sensíveis às diferenças das vozes que se revelam nas enunciações, buscando analisar justamente as polaridades, tensões e incoerências oriundas das variadas posições que as vozes ocupam nas falas. Desse modo, tais pesquisas integram todos os níveis de análise propostos por Murray.

\section{Perspectiva performativa}

A perspectiva performativa no campo da saúde adota um viés francamente construcionista social, no sentido de privilegiar os modos como os conhecimentos sobre saúde e doença são pragmaticamente construídos nas interações discursivas, evitando assumir que as falas dos indivíduos sejam expressões estáveis de pensamentos privados. Essa linha de estudos tende a criticar as pesquisas psicológicas sobre crenças de saúde que enfatizam o papel das cognições, em detrimento dos contextos sociais em que tais crenças e práticas ocorrem. Assim, o que as pessoas afirmam crer e fazer em termos de saúde e doença é considerado "mobilizações de explicações culturalmente disponíveis", portanto, eventos situados, não consistentes, instáveis e não preditivos do comportamento (Willig, 2000, p. 548). Pesquisas nessa perspectiva abarcam níveis distintos de análise das narrativas, conforme molduras teórico-metodológicas particulares. Os estudos que empregam análise de discurso com raízes nas tradições de análise da conversação, etnometodologia e psicologia discursiva, por exemplo, tendem a se concentrar no nível interpessoal e posicional de análise, uma vez que focalizam as interações face a face que moldam as narrativas. Aqui, a ideia é que as subjetividades são produtos transitórios de formações discursivas localizadas; isto é, emergem de negociações travadas nos diferentes contextos discursivos em que se movem os falantes. 
Estudos com narrativas de doentes que sublinham a linguagem em uso analisam em detalhes o trabalho linguístico daqueles que contam suas histórias, de modo a compreender como certas estratégias discursivas são usadas para afirmar ou contestar visões sobre a doença e para alcançar outros fins sociais. Como exemplos, podemos citar o trabalho de Stephens, Budge and Carryer (2002) sobre os repertórios interpretativos usados por mulheres para defender ou não o uso de reposição hormonal; de Seymour-Smith e Wetherel (2006), sobre como casais heterossexuais negociam a doença grave de um dos parceiros e as micropolíticas de gênero envolvidas; de Peel, Parry, Douglas e Lawton (2005), sobre o manejo da dieta entre pacientes com diabetes tipo 2, e de Burr e Chapman (2004), sobre as estratégias discursivas empregadas por mulheres asiáticas migrantes na apresentação de seus sintomas de depressão para equipes profissionais não familiarizadas com sua cultura.

Para Horton-Salway (2001, p. 247), a adoção de uma "psicologia discursiva etnometodologicamente orientada" para estudar as narrativas de portadores de síndrome da fadiga crônica (SFC) provê uma abordagem não cognitivista que analisa em minúcias a atividade prática da narração, isto é, "como os sofredores eles mesmos produzem sentido" sobre a doença e como suas "identidades são construídas como parte desse processo". Neste caso, o estudo mostrou como o narrador empregou estratégias retóricas (como descrições vívidas da saúde mental e psíquica anterior à doença) para modelar uma imagem de credibilidade para si, contra certas versões acusatórias de fingimento ou de vulnerabilidade psíquica lançadas comumente às vítimas de SFC. Para essa autora, cujo trabalho se apoia na psicologia discursiva, a "narrativa de doença pode, portanto, ser analisada como um domínio performativo da ação social, onde a construção da identidade é parte de uma atividade prática de definir uma doença e explicar suas causas" (Horton-Salway, 2001, p. 248).

Outros estudos da linha performativa tendem a focalizar o papel do discurso na constituição da subjetividade e nos processos mais amplos de legitimação e poder. Para Willig (2000), a análise de discurso foucaultiana na área de saúde apresenta dois focos. O primeiro desconstroi os discursos especializados em saúde e doença, no sentido de examinar os processos de dominação de outros saberes e de legitimação de versões par- ticulares de saúde/doença. O segundo busca examinar os efeitos dos discursos especializados dominantes na fala de leigos acerca da saúde e da doença. Ambos os focos dão preferência ao nível ideológico de análise, muitas vezes combinado com o nível posicional.

Pesquisas sobre as narrativas de doenças contadas para os médicos indicam que essas são dependentes das contingências da interação, refletindo muitas vezes a voz hegemônica da medicina. Mishler (2005) mostra como a usual abordagem tecnocrática da prática clínica levou à negligência de uma categoria de narrativas de pacientes sobre sua doença e experiência de tratamento, as "narrativas de resistência". Ilustrando seu argumento a partir do episódio de uma paciente de câncer que se recusou a atender à prescrição de seu médico (inclusive representando-o por meio de um boneco de vodu espetado por agulhas), o autor discute as complexas tensões entre aqueles envolvidos no contexto da prática médica e as suas implicações sobre a ética do cuidado médico.

Noutros estudos, importância é dada às representações midiáticas de doença e como elas forjam o senso comum. A análise de discurso de inspiração foucaultiana situa-se no nível ideológico de análise e está menos preocupada com o que os indivíduos dizem em situações particulares e mais com a forma como o discurso opera como recurso cultural e social. Assim, ao invés de análises detalhadas de segmentos de relatos ou conversação, "os métodos usados são mais taxonômicos, procurando identificar e descrever, para qualquer tópico ou questão, quais são os principais discursos em jogo" (Stainton Rodgers citado por HoltonSalway, 2001, p. 257).

Spink (2007, p. 47) esclarece que a perspectiva construcionista social na psicologia da saúde opera mudanças profundas no modo de conceber a doença: de uma experiência antes entendida como individual, "para um fenômeno coletivo sujeito às forças ideológicas da sociedade" e para um olhar que deixa de privilegiar a ótica médica para abarcar e legitimar visões menosprezadas, como as dos pacientes e de seu grupo cultural específico. Em geral, esses estudos exploram o papel dos discursos na transmissão, manutenção e legitimação de ideologias, doutrinas e valores sustentados à custa do silenciamento e enfraquecimento de outros discursos dissonantes e minoritários. $\mathrm{Na}$ abordagem teórico-metodológica 
das Práticas Discursivas e produção de sentido, tal como desenvolvida por Spink et al. (2004), obtémse uma posição integradora entre o nível macro e o micro de análise da linguagem em uso, à medida que se busca "trabalhar a interface entre os aspectos performáticos da linguagem e as condições de produção, entendidas tanto no contexto social e interacional, quanto no sentido foucaultiano de construções históricas" (Spink \& Medrado, 2004, p. 43). Essa abordagem pretende realizar pesquisas na interface de tempos históricos: o tempo longo (conteúdos culturais legados no curso da civilização), tempo vivido (das linguagens aprendidas nos processos de socialização, na história pessoal e na pertença a grupos sociais) e tempo curto (processos face a face em que se produzem sentidos polissêmicos).

Com o objetivo de descrever sentidos de doença mental produzidos por participantes de um grupo terapêutico, Guanaes e Japur (2005) adotam um posicionamento pragmático e crítico. O trabalho não tem a pretensão de investigar a veracidade das descrições dos participantes, nem mesmo propor um novo entendimento acerca da doença mental. Focalizando o caráter performático da linguagem, as autoras se preocupam fundamentalmente com as práticas sociais que esses discursos sobre doença mental sustentam, com os modos de relacionamento que promovem e com as identidades que se constroem a partir destas descrições.

A tendência desses estudos é de explorar os repertórios interpretativos e discursos empregados pelos participantes, bem como as negociações travadas nas interações, sempre compreendendo as falas como práticas e conhecimentos em processo e não como meio de acesso a uma verdade anterior ou autêntica. É o caso do estudo de Borges e Japur (2005) sobre os sentidos de saúde e doença produzidos em um grupo comunitário, e o de Menegon (1998), sobre a significação da menopausa.

\section{CONSIDERAÇÕES FINAIS: Confluências entre perspectivas e implicações para a pesquisa}

As perspectivas, métodos e níveis de análise em pesquisas sobre a relação entre saúde/ doença, linguagem e subjetividade, discutidos neste trabalho, emergem no contexto mais amplo de ascensão das abordagens qualitativas nas ciências da saúde e, mais particularmente, em resposta às críticas não-fundacionalistas e construcionistas aos modelos investigativos em psicologia. Tais críticas, oriundas de diferentes movimentos intelectuais e abordagens tais como a psicologia e filosofia narrativas, feminismo, etnometodologia, análise do discurso, entre outros, contribuíram para o florescimento de teorias e práticas científicas mais focadas nos processos relacionais, linguísticos e pragmáticos envolvidos na produção subjetiva.

A revisão das propostas de Smith e Sparkes (2008) e de Murray (2000), aqui esboçada, teve o propósito de apresentar os fundamentos teóricometodológicos de pesquisas qualitativas no campo da saúde, de modo a esclarecer os princípios subjacentes às formas de problematização e às estratégias de investigação empírica. Como advertem Smith e Sparkes, sua classificação das perspectivas não tem perfil rígido nem hierárquico, pretendendo apenas fornecer visibilidade aos estudos e abordagens contrastantes no campo.

Algumas conclusões podem ser extraídas da leitura e classificação dos relatos de pesquisa selecionados. Grosso modo, podemos assinalar as principais convergências entre as cinco perspectivas propostas por Smith e Sparkes: crença na modelação sociocultural das identidades, repúdio à visão essencialista ou substantiva da identidade pessoal e coletiva, visão multidimensional e contextualizada das subjetividades, reconhecimento do papel constitutivo dos discursos e narrativas (históricos, políticos, culturais) nos processos de formação subjetiva e foco na linguagem. Quanto ao contexto específico da pesquisa em saúde e doença, os relatos das investigações aqui revisados tendem a abandonar a exclusividade da pesquisa biomédica, deslocando sua atenção para a construção social da doença (e saúde). O interesse dirige-se para a produção de sentidos sobre a experiência do adoecer, nos níveis mais locais ou mais amplos dos discursos e narrativas negociados sociocultural e historicamente. Essa tendência realça o poder (re)construtivo das narrativas, seja focalizando o trabalho biográfico individual por ocasião do adoecimento, seja enfatizando o papel das narrativas públicas e metanarrativas nos modos como indivíduos e grupos concebem a doença e orientam-se no sentido de seu enfrentamento.

De fato, embora as perspectivas aqui delineadas exibam contrastes ontológicos, episte- 
mológicos e teórico-metodológicos, observa-se um perfil fortemente integrador em muitos trabalhos, que pode ser acompanhado no modo como os autores fundamentam seus estudos e dialogam com outros autores representativos de vários quadros teóricos e campos disciplinares. Pode-se observar que as afinidades teóricas são mais visíveis entre algumas perspectivas, dada a combinação de uma posição não fundacionalista (ou anti-fundacionalista), uma ontologia relativista e uma epistemologia construtivista. Nesse caso, podemos aproximar com mais comodidade pesquisas das quatro últimas perspectivas e efetuarum diálogo promissor entre teóricos, tais como Harré (intersubjetivista), Gubrium e Holstein (recursos historiados), Hermans (dialógica), K. Gergen (performativa).

A perspectiva psicossocial, nesse caso, parece distanciar-se das demais em função da adoção de uma posição fundacionalista, de uma ontologia realista e de uma epistemologia objetivista. Essas crenças básicas não impedem que, em algumas questões específicas, autores como McAdams (da linha psicossocial) possam convergir com uma perspectiva, por exemplo, dialógica. A título de ilustração, podem-se apontar convergências em McAdams e Hermans quanto à atenção dada a processos internos na formação do self. Para Hermans, as vozes que dialogam no self não são somente externas e a mente individual (negligenciada nas demais perspectivas de foco relacional) permanece relevante nas pesquisas.

As confluências tornam a diferenciação das três últimas perspectivas (recursos historiados, dialógica e performativa) particularmente difícil, uma vez que as três concebem as narrativas como ações sociais contingentes aos contextos de interação social e estão especialmente atentas às questões de poder e desigualdade envolvidas na sua produção e circulação. Com efeito, a distinção entre as três perspectivas é mais clara no plano teórico (especialmente no que concerne à gradativa ênfase sobre a dimensão social/ relacional da subjetividade) do que no empírico, quando se examinam os problemas, métodos e resultados de pesquisas concretas. $\mathrm{Na}$ exposição das molduras teóricas, o que se observa nos relatos é o apoio a autores, obras e abordagens de forma intercambiável. Assim, Foucault e Bakhtin podem orientar pesquisas nas três vertentes, com objetivos e procedimentos bastante similares. Um exemplo ilustrativo é o da abordagem das Práticas Discursivas, de Spink e Medrado (2004), que assume uma epistemologia construcionista mais próxima da vertente performática, uma posição política orientada por estudos de Foucault e uma atenção à linguagem e aos processos discursivos, inspirada em Bakhtin. A partir de qualquer uma das três perspectivas, o pesquisador na área de saúde buscará desnaturalizar saberes e práticas (leigos e científicos) que orientam a ação de indivíduos e coletividades no contexto da saúde/doença, em geral empenhado em favorecer novos conhecimentos e práticas menos desiguais e opressores.

A revisão empreendida leva a concordar com Murray (2000) quando afirma que o desafio dos estudos narrativos hoje parece ser a integração de diferentes níveis de análise-pessoal, interpessoal, posicional e ideológico -, de modo a atender às particularidades da problemática sob investigação. Em geral, as pesquisas, embora selecionem um desses níveis como foco, mostram-se delineamentos multifacetados que combinam dois ou mais níveis de análise e, às vezes, estratégias micro e macroanalíticas. As narrativas dos informantes, mesmo nos estudos enquadrados na perspectiva psicossocial (a mais focalizada na dimensão individual, segundo Smith e Sparkes), são concebidas como produções situadas e interativas, de tal modo que os contextos mais ou menos amplos que condicionam a narração não deixam de ser objeto de exame.

Concluímos que, embora haja certo purismo nas discussões metateóricas travadas entre representantes das linhagens aqui esboçadas, quando se trata do campo das práticas de pesquisa e de aplicação observa-se mais diálogo que oposição. É possível acompanhar o potencial de pesquisa que a abordagem narrativa apresenta no campo da experiência pessoal do adoecer, especialmente quanto ao impacto da enfermidade sobre o self, nos estudos sobre a experiência cultural da saúde e da doença e na compreensão das relações de poder e dominação negociadas nos saberes e práticas de saúde disponíveis.

\section{AGRADECIMENTOS}

Agradecemos o apoio da Fundação Cearense de Apoio ao Desenvolvimento Científico (FUNCAP-CE) a este trabalho. 


\section{REFERÊNCIAS}

Borges, C. C., \& Japur, M. (2005). Promover e recuperar saúde: Sentidos produzidos em grupos comunitários no contexto do Programa de Saúde da Família. Interface (Botucatu), 9(18), 507-519.

Bury, M. (1982). Chronic illness as biographical disruption. Sociology of Health and Illness, 4(2), 167-182.

Burr, J., \& Chapman, T. (2004). Contextualising experiences of depression in women from South Asian communities: A discursive approach. Sociology of Health and Illness, 26(4), 433-452.

Caprara, A., \& Veras, M. S. C. (2004). Hermenêutica e narrativa: A experiência de crianças com epidermólise bolhosa congênita. Interface: Comunicação, Saúde, Educação, 9(16),131-146.

Chapple, A., \& Ziebland, S. (2002). Prostrate cancer: Embodied experience and perceptions of masculinity. Sociology of Health and Illness, 24(6), 820-841.

Charmaz, K. (1983). Loss of self: A fundamental form of suffering in the chronically ill. Sociology of Health and Illness, 5(2), 168-195.

Crossley, M. L. (2000). Narrative Psychology, trauma and the study of self/identity. Theory Psychology, 10(4), 527-546.

Durgahee, (2002). Dialogism in action: Talking fact and fiction. Journal of Psychiatric and Mental Health Nursing, 9(4), 419-425.

Edwards, C., Thompson, A., \& Blair, A. (2007). An overwhelming illness: Women's experiences of learning to live with chronic fatigue syndrome/ myalgic encephalomyelitis. Journal of Health Psychology, 12(2), 203-214.

Ezzy, D. (2000). Illness narratives: Time, hope and HIV. Social Science and Medicine, 50, 205-217.

Geertz, C. (1999). O saber local. Petrópolis: Vozes.

Giddens, A. (1991). Modernity and self-identity: Self and society in the late modern age. Cambridge: Polity Press.

Goodman, D., Morrisey, S., Graham, D., \& Bossingham, D. (2005). Illness repesentations of sistemic lupus erithematosus. Qualitative Health Research, 15(5), 606-619.
Guanaes, C., \& Japur, M. (2005). Sentidos de doença mental em um grupo terapêutico e suas implicações. Psicologia: Teoria e Pesquisa, 21(2), 227-235.

Hermans, H. J. M. (2001). The dialogical self: Toward a theory of personal and cultural positioning. Culture Psychology, 7(3), 243-281.

Holstein, J. A., \& Gubrium, J. F. (2000). The selves we live by: Narrative identity in a postmodern world. New York, Oxford: Oxford University Press.

Horton-Salway, M. (2001). Narrative identities and the management of personal accountability in talk about ME: A discursive psychology approach to illness narrative. Journal of Health Psychology, 6(2), 247-259.

Kierans, C. (2005). Narrating kidney disease: The significance of sensation and time in the emplotment of patient experience. Culture, Medicine and Psychiatry, 29(3), 341-359.

Kleinman, A. (1988). The illness narratives: Suffering, healing and the human condition. New York: Basic Books.

Lysaker, P. H., \& Lysaker, J. T. (2002). Narrative structure in psychosis: Schizophrenia and disruptions in the dialogical self. Theory and Psychology, 12(2), 207-220.

McIntosh, J., \& McKecaney, N. (2000). Addicts' narratives of recovery from drug use: Constructing a non-addict identity. Social Science and Medicine, 50, 1501-1510.

Menegon, V. M. (1998). Menopausa: Imaginário social e conversa do cotidiano. Dissertação de Mestrado, Pontifícia Universidade Católica de São Paulo, São Paulo.

Mishler, E. G. (2005). Patients stories, narratives of resistance and the ethics of human care: A la recherché du temps perdu. Health: An Interdisciplinary Journal for the Social Study of Health, Illness and Medicine, 9(4), 431-451.

Murray, M. (2000). Levels of narrative analysis in health psychology. Journal of Health Psychology, 5(3), 337-347.

Nochi, M. (2000). Reconstructing self-narratives in coping with traumatic brain injury. Social Science and Medicine, 51(12), 1795-1804. 
Peel, E., Parry, O., Douglas, M., \& Lawton, J. (2005). Taking the biscuit? A discursive approach to managing diet in type 2 diabetes. Journal of Health Psychology, 10(6), 779-791.

Rajaran, S. S. (1997). Experience of hypoglycemia among insulin dependent diabetics and its impact on the family. Sociology of Health and Illness, 19(3), 281-296.

Riessman, C. K. (1993). Narrative analysis. New Delhi: Sage Publications.

Rober, P., Elliott, R., Buysse, A., Loots, G., \& De Corte, E, K. (2008). Positioning in the therapist's inner conversation: A dialogical model based on a grounded theory analysis of therapist reflections. Journal of Marital and Family Therapy, 34(3), 406-421.

Sarbin, T. R. (Ed.). (1986). Narrative psychology: The storied nature of human conduct. Westport, Connecticut: Praeger Publishers.

Schweder, R. A., \& Sullivan, M. A. (1993). Cultural Psychology: Who needs it? Annual Review of Psychology, 44, 497-523.

Seikkula, J., \& Trimble, D. (2005). Healing elements of therapeutic conversation: Dialogue as an embodiment of love. Family Process, 44(4), 461-475.

Seymour-Smith, S., \& Wetherell, M. (2006). What he hasn't told you: Investigating the micro-politics of gendered support in heterosexual couples' coconstructed accounts of illness. Feminism and Psychology, 16(1), 105-127.

Shapiro, S., Angus, L., \& Davis, C. (1997). Identity and meaning in the experience of cancer: Three narrative themes. Journal of Health Psychology, 2(4), 539-554.

Silva, A. P. S. da. (2003). (Des)continuidade no envolvimento com o crime: Construção de identidade narrativa de ex-infratores. São Paulo: IBCCRIM.

Smith, B., \& Sparkes, A. C. (2008). Contrasting perspectives on narrating selves and identites: An invitation to dialogue. Qualitative Research, 8(1), 5-35.

Smith, J. A., \& Osborn, M. (2008). Interpretative phenomenological analysis. In J. A. Smith (Ed.). Qualitative psychology: A practical guide to research methods (pp. 53-110). Los Angeles: Sage.
Somers, M. (1994). The narrative constitution of identity: A relational and network approach. Theory and Society, 23(5), 605-649.

Sparkes, A. C., \& Smith, B. (2002). Sport, spinal cord injury, embodied masculinities and the dilemmas of narrative identity. Men and Masculinities, 4(3), 258-284.

Spink, M. J. (Org.). (2004). Práticas discursivas e produção de sentidos no cotidiano. São Paulo: Cortez.

Spink, M. J. (2007). Psicologia social e saúde: Práticas, saberes e sentidos. Petrópolis: Vozes.

Spink, M. J., \& Medrado, B. (2004). Produção de sentidos no cotidiano: Uma abordagem teóricometodológica para análise das práticas discursivas. In M. J. Spink (Org.). Práticas discursivas e produção de sentidos no cotidiano (pp. 41-61). São Paulo: Cortez.

Stanley, L., \& Temple, E. B. (2008). Narrative methodologies: Subjects, silences, re-readings and analyses. Qualitative Research, 8(3), 275-281.

Stephens, C., Budge, R. C., \& Carryer, J. (2002). What is this thing called hormone replacement therapy? Discursive construction of medicaton in situated practice. Qualitative Health Research, 12(3), 347-359.

Sutton, R., \& Treolar, C. (2007). Chronic illness experiences, clinical markers and living with hepatitis C. Journal of Health Psychology, 12(2), 330-340.

Williams, G. (2001). The genesis of chronic illness: narrative reconstruction. In L. P. Hinchman \& S. K. Hinchman (Ed.). Memory, identity, community: The idea of narratives in the human sciences (pp. 185-212). Albany: State University of New York Press.

Willig, C. (2000). A discourse-dynamic approach to the study of subjectivity in health psychology. Theory Psychology, 10(4), 547- 570.

Young, B., Dixon-Woods, M., Findlay, M., \& Heney, D. (2002). Parenting in a crisis: Conceptualizing mothers of children with cancer. Social Science and Medicine, 55(10), 1835-1847.

Recebido: 19/05/2009 Received: 05/19/2009

Aprovado: 28/08/2009 Approved: 08/28/2009 